\title{
Продуктивность виноградников с различными формами кустов при полуукрывной культуре возделывания
}

Надежда Александровна Сироткина, канд. с.-х. наук, ст. науч. сотр. лаб. агротехники, nad.sirotckina2017@jandex.ru; тел 8-904-349-99-27

Всероссийский научно-исследовательский институт виноградарства и виноделия - филиал Федерального государственного бюджетного научного учреждения Федеральный ростовский аграрный научный центр, пр. Баклановский, 166, Новочеркасск, Ростовская обл., Россия, 346421

В статье приведены данные исследований трех форм виноградных растений при полуукрывной культуре возделывания за 2005-2012 гг. На винограде сорта Первенец Магарача изучались формы: двусторонний косой кордон, односторонний горизонтальный кордон с резервным рукавом, двусторонний горизонтальный кордон с резервным рукавом. Виноградники 1986 года посадки, корнесобственные, неорошаемые, с площадью питания 3 x 1,5 м. В среднем за годы исследований по продуктивности насаждений выделена форма кустов «двусторонний горизонтальный кордон с резервным рукавом». Урожайность виноградников составила 14,2 т/га за счет более высокой нагрузки растений плодоносными побегами и их плодоносности.

Ключевые слова: культура винограда; форма кустов; штам6; рукав; нагрузка; побеги; плодоносность; урожайность; однолетний прирост.

Ц елью работы являлось выявление наиболее продуктивной формы растений винограда при полуукрывной культуре возделывания.

Работу проводили в соответствии с методикой агротехнических исследований [1].

Способ защиты виноградных растений от критически низких температур возделываемых сортов винограда окучиванием известен еще с 30-х годов прошиого столетия. Изучение полуукрывной культуры проводили в разАичных регионах рискованного виноградарства: в Крыму [2, 3], в Чеченской республике [4], на Кубани [5, 6], в Северном Аагестане $[7,8]$, на Аону [9], а также в северных районах Китая [10].

Полуукрывная культура винограАа основана на применении комбинированных авухъярусных форм, в которых нижний ярус укрывают на зиму, а верхний - нет. Рекоменауется Аця

\footnotetext{
Как цитировать эту статью:

Сироткина Н.А. Продуктивность виноградников с различными формами кустов при полуукрывной культуре возделывания// «Магарач» Виноградарство и виноделие, 2019; 21(2); С. 109-112. DOI 10.35547/IM.2019.21.2.006

\section{How to cite this article:}

Sirotkina N.A. Productivity of vineyards with differently trained vines under semi-covered vine growing. Magarach. Viticulture and Winemaking, 2019; 21(2); pp. 109-112. DOI 10.35547/IM.2019.21.2.006

удК 634.85:631.524.8/.527.6:631.541.11

Поступила 29.10.2018

Принята к публикации 16.05.2019

(C) Авторы, 2019
}

\section{O R I I A L A R T I C L E \\ Productivity of vineyards with differently trained vines under semi- covered vine growing}

Nadezhda Alexandrovna Sirotkina
All-Russian Research Institute of Viticulture and Winemaking- branch of the Federa
State Budgetary Scientific Institution Federal Rostov Agricultural Research Center,

State Budgetary Scientific Institution Federal Rostov Agricultural Resear
166 Baklanovsky Ave., 346421 Novocherkassk, Rostov region, Russia

The article summarizes data from the study conducted in 2005-2012 on three shapes of vine plants under semi-covered vine growing. The following shapes were studied on the cultivar 'Pervenets Magaracha': bilateral oblique cordon, unilateral horizontal cordon with a reserve arm, bilateral horizontal cordon with a reserve arm. The vineyards' profile: planted in 1986, own-rooted, non-irrigated, with the growing space of $3 \times 1.5 \mathrm{~m}$. On average, the vine trained as bilateral horizontal cordon with reserve arm stood out over the years of plantation productivity studies. The harvest of the vineyards amounted to $14.2 \mathrm{t} / \mathrm{ha}$ due to higher load of plants with fertile shoots and their fruitfulness..

Key words: viticulture, vine shape, trunks, arm, load, shoots, fruitfulness, yield, one-year increment.

применения на сортах и участках с повторяемостью критически низких температур воздуха Аһя культивируемых сортов не более $20 \%$, т.е. одного раза в 5 мет. В условиях Ростовской обцасти применима Аля сортов с повышенной морозостойкостью: Степняк, Цветочный, Голубок, Восторг, Бианка, Первенец Магарача и Ар. Полуукрывные формы кустов бывают:

- с низким или приземным расположением структурных элементов резервной части с укрывкой резервных моз слоем земли 25-35 см. При повреждении неукрываемой части кустов ее восстанавливают за 1-2 года за счет побегов резервной основы;

- с относительно высоким расположением резервной части кустов в виде односторонних УАлиненныХ рукавов. После сильных поврежАений неукрытую часть куста удаляют, резервный рукав поднимают и размещают в вертикальном положении, а цозы поАрезают на 6-12 глазков. Из стрелки восстановцения формируют новый резервный рукав. При таком режиме куст восстанавливается в гоА поврежАения морозами без снижения урожайности.

На наш взгляА, очень пластичной формой куста, Аостаточно уАачно вписывающейся в полуукрывную культуру, явцяется «Авусторонний косой корАон», состоящий из Авух накмоненных в разные стороны рукавов с равномерно размещенными на них пмодовыми звеньями. Осенью, после уборки урожая нижнюю часть куста окучивают валом земли (35-40 см), при этом не требуется специацьной подготовки кустов К укрывке. В случае симьного поврежАения Аоз, размещенных наА валом земли, зимними морозами, восстановление структуры куста веАут из цоз, которые находимись поА валом, в тот же гоА, при незначительном снижении урожая (в преАелах 10-20\%) по сравнению с укрывными виноградниками [11].

На протяжении восьми мет исследовали три формы кустов полуукрывной культуры на сорте винограда Первенец Магарача: Авусторонний косой корАОН [12], оАносторонний и Авусторонний горизонтацьные кордоны с резервными рукавами и сучками восстановления [13]. Весной 2005 года эти формы были созданы путем реконструкции укрывных корнесобственных виноградников 1986 года посадки с площадью питания 3 х 1,5 м. Высота штамба в фор- 
Таблица 1. Нагрузка побегами, плодоносными побегами и гроздями

Table 1. Vine load with shoots, fertile shoots and bunches

\begin{tabular}{|c|c|c|c|c|c|c|c|c|c|}
\hline \multirow{4}{*}{ ГоА } & \multicolumn{9}{|c|}{ Форма куста } \\
\hline & \multicolumn{3}{|c|}{ Авусторонний косой корАон } & \multicolumn{3}{|c|}{$\begin{array}{l}\text { односторонний горизонтальный кор- } \\
\text { Аон с резервным рукавом }\end{array}$} & \multicolumn{3}{|c|}{ 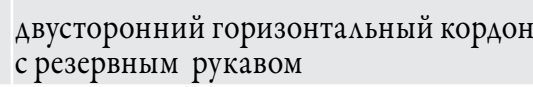 } \\
\hline & \multicolumn{3}{|c|}{ нагрузка, шт./куст } & \multicolumn{3}{|c|}{ нагрузка, шт./куст } & \multicolumn{3}{|c|}{ нагрузка, шт./куст } \\
\hline & побегами & $\begin{array}{l}\text { пцодоносны- } \\
\text { ми побегами }\end{array}$ & грозАями & побегами & $\begin{array}{l}\text { пмодоносны- } \\
\text { ми побегами. }\end{array}$ & грозАями & побегами & $\begin{array}{l}\text { плодоносны- } \\
\text { ми побегами }\end{array}$ & грозАями \\
\hline 2005 & 25 & 17 & 28 & 17 & 11 & 19 & 22 & 16 & 28 \\
\hline 2006 & 30 & 22 & 35 & 11 & 7 & 13 & 18 & 12 & 20 \\
\hline 2007 & 34 & 28 & 52 & 37 & 34 & 63 & 43 & 38 & 77 \\
\hline 2008 & 41 & 31 & 57 & 34 & 26 & 54 & 38 & 28 & 57 \\
\hline 2009 & 40 & 25 & 37 & 40 & 32 & 54 & 40 & 32 & 53 \\
\hline 2010 & 41 & 37 & 63 & 40 & 31 & 55 & 40 & 36 & 58 \\
\hline 2011 & 36 & 20 & 30 & 42 & 31 & 48 & 47 & 36 & 56 \\
\hline 2012 & 31 & 20 & 37 & 41 & 31 & 50 & 50 & 39 & 62 \\
\hline среднее & 35 & 25 & 42 & 33 & 25 & 44,5 & 37 & 30 & 51 \\
\hline
\end{tabular}

мах с горизонтацьными кордонами составцяца 100 см.

В 2005 году путем реконструкции укрывных насаждений сорта Первенец Магарача быми созданы помуукрывные формы растений с испоцьзованием пригодной многометней древесины и порослевых побегов от головы куста. В январе 2006 года температура возАуха опустилась $а$ о $-28^{\circ} \mathrm{C}$ и неукрывная часть кустов вымерзла. Поскольку резервная основа штамбовых формировок состояла в основном из однолетних побегов с вызревшими пасынками, то и нагрузка побегами, плодоносными побегами и гроздями в этот вегетационный период по вариантам опыта быми ниже по сравнению с нагрузкой растений с формой Авусторонний косой корАОН, гАе ААя формирования плеч корАона испо ьзовацись в основном многолетние рукава (табц. 1). В 2007 и 2008 гг. регулироваци нагрузку, удамяя слабые и Авойниковые побеги, не преслеАуя цели выровнять ее между вариантами опыта Аця выявления потенциацьной возможности растений с разными формами в отношении нагрузки зелеными побегами.

Ава последующих года $(2009,2010)$ выравнивали нагрузку побегами в предемах 40 шт. на одно растение. Несмотря на более высокий процент плодоносных побегов в среАнем за эти гоАЫ (Авусторонний косой корАОН - 76\%; оАносторонний и Авусторонний горизонтацьные кордоны - 80 и $85 \%$ ) и более высокие Аанные по плодоносности $(1,59 ; 1,74$ и 1,64 соответственно) этих побегов, на растениях со штамбовыми формами было отмечено образование пасынковых побегов. Так, по нашему мнению, виноградное растение реагировало на недостаточную нагрузку зелеными побегами. В Аамьнейшем регулировать нагрузку полноценными земеными побегами мы не стали.

В среднем за годы исследований самые высокие показатели нагрузки побегами, плодоносными побегами и грозАями отмечены в насаждениях с формой винограАных кустов Авусторонний горизонтацьный кордон с резервным рукавом.

Такая же закономерность сохранимась и в показа- телях нагрузки виноградных кустов урожаем (табл. 2).

Низкие показатели среАней массы грозди в 2009

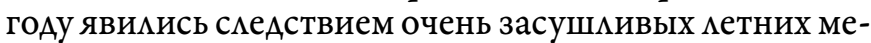
сяцев, когда в июне выпацо осаАков в 5,7; а в августе - в 5,6 раза ниже среАнемноголетней нормы.

В среднем за годы исследований, самая низкая масса грозАи в опыте отмечена в варианте с формой кустов Авусторонний косой кордон (115 г). На 9 г выше этот показатемь в варианте с формой Авусторонний горизонтацьный корАон с резервным рукавом (124 г); самой крупной грозАью в среАнем за 8 иет исслеАований отАичиАись растения с формой оАносторонний кордон и резервной основой (126,5 г). Но, поскольку на кустах этого варианта опыта гроздей сформировамось меньше, то и по урожайности оАного растения и насажАений в целом, винограАники уступими насаждениям с формой Авусторонний горизонтальный кордон - 12,5 против 14,2 т/га. Самой низкой в опыте продуктивностью отличимись виноградники с формой кустов Авусторонний косой кордон (10,7 т/га). Это закономерно, т.к. в этом варианте отмечена самая низкая в опыте нагрузка грозАями при самой низкой ее массе (коэффициент корремяции межАу урожайностью и нагрузкой грозАями равен 0,99 , урожайности и средней массы грозАи - 0,77). Разница по урожайности межАу крайними вариантами составима 3,5 т/га.

Как нагрузка виноградников побегами и урожаем отразилась на однолетнем приросте видно из табл. 3. По средним из восьмилетних Аанных прослеживается четкая закономерность снижения объема побега с увеличением их количества на растении $(r=-0,97)$.

Так, в варианте с формой кустов односторонний горизонтацьный кордон с резервным рукавом, при нагрузке земеными побегами 33 шт. на растение, объем одного побега составим $15,6 \mathrm{~cm}^{3}$, в варианте с кустами, сформированными по типу Авусторонний косой корАон, эти показатели составими 35 побегов и 13,4 см соответственно. На растениях, имеющих форму Авусторонний горизонтацьный кордон с резервным рука- 
Таблица 2. Урожайность виноградников

Table 2. Vineyards' fertility

\begin{tabular}{|c|c|c|c|c|c|c|c|c|c|c|c|c|}
\hline \multirow[b]{3}{*}{ ГоА } & \multicolumn{12}{|c|}{ Форма куста } \\
\hline & \multicolumn{4}{|c|}{ Авусторонний косой корАон } & \multicolumn{4}{|c|}{$\begin{array}{l}\text { оАносторонний горизонтальный корАон } \\
\text { с резервным рукавом }\end{array}$} & \multicolumn{4}{|c|}{$\begin{array}{l}\text { Авусторонний горизонтальный корАон с } \\
\text { резервным рукавом }\end{array}$} \\
\hline & $\begin{array}{l}\text { количе- } \\
\text { ство гроз- } \\
\text { Аей на } \\
\text { куст, шт. }\end{array}$ & $\begin{array}{l}\text { среАняя } \\
\text { масса } \\
\text { грозди, І }\end{array}$ & $\begin{array}{l}\text { урожай с } \\
\text { куста, кг }\end{array}$ & $\begin{array}{l}\text { сурожай } \\
\text { га, т }\end{array}$ & $\begin{array}{l}\text { коли- } \\
\text { с чество } \\
\text { гроздей на } \\
\text { куст, шт. }\end{array}$ & $\begin{array}{l}\text { средняя } \\
\text { масса } \\
\text { грозАИ, Г }\end{array}$ & $\begin{array}{l}\text { урожай с } \\
\text { куста, кг }\end{array}$ & $\begin{array}{l}\text { урожай } \\
\text { с га, т }\end{array}$ & $\begin{array}{l}\text { количе- } \\
\text { ство гроз- } \\
\text { Аей на } \\
\text { куст, шт. }\end{array}$ & $\begin{array}{l}\text { средняя } \\
\text { масса } \\
\text { грозАи, Г }\end{array}$ & $\begin{array}{l}\text { урожай с } \\
\text { куста, кг }\end{array}$ & $\begin{array}{l}\text { урожай с } \\
\text { га, т }\end{array}$ \\
\hline 2005 & 28 & 118 & 3,4 & 7,6 & 19 & 128 & 2,6 & 5,8 & 28 & 150 & 4,0 & 8,9 \\
\hline 2006 & 35 & 121 & 4,2 & 9,3 & 13 & 151 & 2,0 & 4,4 & 20 & 141 & 2,8 & 6,2 \\
\hline 2007 & 52 & 144 & 7,5 & 16,7 & 63 & 124 & 7,8 & 17,3 & 77 & 122 & 9,4 & 20,9 \\
\hline 2008 & 57 & 100 & 5,7 & 12,7 & 54 & 136 & 7,3 & 16,2 & 57 & 127 & 7,2 & 16,0 \\
\hline 2009 & 37 & 95 & 3,5 & 7,8 & 54 & 86 & 4,6 & 10,2 & 53 & 82 & 4,3 & 9,6 \\
\hline 2010 & 63 & 102 & 6,4 & 14,2 & 55 & 119 & 6,5 & 14,4 & 58 & 118 & 6,8 & 15,1 \\
\hline 2011 & 30 & 100 & 3,0 & 6,7 & 48 & 130 & 6,2 & 13,8 & 56 & 126 & 7,1 & 15,8 \\
\hline 2012 & 37 & 138 & 5,1 & 11,3 & 50 & 138 & 6,9 & 15,3 & 62 & 130 & 8,1 & 18,0 \\
\hline среднее & 42 & 115 & 4,8 & 10,7 & 44,5 & 126,5 & 5,6 & 12,5 & 51 & 124 & 6,4 & 14,2 \\
\hline
\end{tabular}

Таблица 3. Параметры однолетнего прироста

Table 3. One year increment parameters

\begin{tabular}{|c|c|c|c|c|c|c|c|c|c|c|c|c|}
\hline \multirow{3}{*}{$\Gamma_{A}$} & \multicolumn{12}{|c|}{ Форма куста } \\
\hline & \multicolumn{4}{|c|}{ Авусторонний косой корАон } & \multicolumn{4}{|c|}{$\begin{array}{l}\text { оАносторонний горизонтальный } \\
\text { корАон с резервным рукавом }\end{array}$} & \multicolumn{4}{|c|}{$\begin{array}{l}\text { Авусторонний горизонтальный кордон } \\
\text { с резервным рукавом }\end{array}$} \\
\hline & $\begin{array}{l}\text { коли- } \\
\text { чество } \\
\text { побе- } \\
\text { гов, шт. }\end{array}$ & $\begin{array}{l}\text { V } 1 \text { побе- } \\
\text { га, } \text { см }^{3} \\
\end{array}$ & $\begin{array}{l}\text { - } \text { прироста } \\
\text { куста, } \text { см }^{3}\end{array}$ & $\begin{array}{l}\% \text { вы- } \\
\text { зрева- } \\
\text { ния }\end{array}$ & $\begin{array}{l}\text { коли- } \\
\text { чество } \\
\text { побегов, } \\
\text { шт. }\end{array}$ & $\begin{array}{l}\text { V } 1 \text { побе- } \\
\text { га, см }{ }^{3}\end{array}$ & $\begin{array}{l}\text { V прироста } \\
\text { куста, } \text { см }^{3}\end{array}$ & $\begin{array}{l}\text { \% вызре- } \\
\text { вания }\end{array}$ & $\begin{array}{l}\text { коли- } \\
\text { чество } \\
\text { побегов, } \\
\text { шт. }\end{array}$ & $\begin{array}{l}\text { V } 1 \text { побе- } \\
\text { га, } \text { cm }^{3}\end{array}$ & $\begin{array}{l}\text { V прироста } \\
\text { куста, } \text { см }^{3}\end{array}$ & $\begin{array}{l}\text { \% вы- } \\
\text { зрева- } \\
\text { ния }\end{array}$ \\
\hline 2005 & 25 & 16,6 & 415,3 & 60 & 17 & 25,1 & 426,9 & 63 & 22 & 17,7 & 389,1 & 58 \\
\hline 2006 & 30 & 17,5 & 526,3 & 57 & 11 & 34,2 & 376,1 & 72 & 18 & 14,0 & 251,7 & 70 \\
\hline 2007 & 34 & 17,5 & 492,8 & 44 & 37 & 18,6 & 557,4 & 38 & 44 & 7,4 & 325,0 & 30 \\
\hline 2008 & 40 & 9,0 & 362,8 & 53 & 34 & 11,8 & 376,6 & 53 & 37 & 9,1 & 336,7 & 58 \\
\hline 2009 & 40 & 9,0 & 360,0 & 54 & 40 & 6,6 & 262,8 & 43 & 40 & 6,7 & 467,6 & 48 \\
\hline 2010 & 41 & 10,8 & 431,6 & 45 & 40 & 11,8 & 470,4 & 43 & 40 & 9,0 & 390,0 & 38 \\
\hline 2011 & 36 & 14,0 & 501,4 & 61 & 42 & 12,1 & 507,4 & 55 & 47 & 12,6 & 593,1 & 41 \\
\hline 2012 & 31 & 16,8 & 251,4 & 62 & 41 & 11,6 & 476,7 & 57 & 50 & 14,4 & 719,6 & 49 \\
\hline среднее & 35 & 13,4 & 470,1 & 54 & 33 & 15,6 & 515,0 & 49 & 37 & 10,9 & 402,8 & 49 \\
\hline
\end{tabular}

вом, развилось в среднем самое большое количество (37 шт.) побегов в опыте при самом низком их объеме $\left(10,2 \mathrm{~cm}^{3}\right)$. Значения объема прироста растения в це-

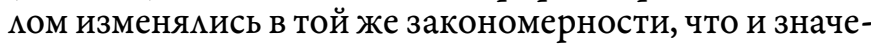
ния объема одного побега, несмотря на значительную разницу в количестве побегов. Процент вызревания оАнолетнего прироста в среднем за годы провеАения эксперимента по вариантам отличался незначительно. Вызревшей мозы вполне хватало Аля подАержания заАанной формы кустов, тем более что зАесь применямась короткая (3-4 глазка) обрезка.

На основании результатов проведенных исслеАований можно сАелать вывоА, что в пределах опыта на виноградниках сорта Первенец Магарача более высокой продуктивностью отмичалась форма кустов
Авусторонний горизонтальный корАон с резервным рукавом и сучком восстановления.

\section{Источники финансирования}

Не указаны.

\section{Financing source}

Not specified.

\section{Конфликт интересов}

Не заявлен.

\section{Conflict of interests}

Not declared.

\section{Список литературы / References}

1. Агротехнические исследования по созданию интенсивных виноградных насаждений на промышленной основе /Ответственный редактор Б. А. Музыченко. - Новочеркасск, 1978. - 175 с. 
Agrotexnicheskie issledovaniya po sozdaniyu intensivnyb vinogradnyb nasazbdenij na promyshlennoj osnove. Novocherkassk. 1978. p.175. (in Russian)

2. Васюта, Г.Г. Формирование кустов при полуукрывной культуре винограда / Г.Г. Васюта // Садоводство, виноградарство и виноделие Молдавии. - 1963. - №3. - С. 25-27.

Vasyuta G.G. Formirovanie kustov pri poluukryvnoj kulture vinograda [Formation of bushes in semi-continuous culture of grapes horticulture, viticulture and winemaking in Moldova] // Sadovodstvo, vinogradarstvo i vinodelie Moldavii. - 1963. №3. pp. 25-27. (in Russian) 3. Дубинко, В. К. Двухъярусная полуукрывная формировка винограда на высокой шпалере / В.К. Дубинко, О.Д. Селюх //Садоводство, виноградарство и виноделие Молдавии. - 1973. - № 12. - С. 17-18.

Dubinko V.K. Selyub O.D. Duubyarusnaya poluukryvnaya formirovka vinograda na vysokoj shpalere // Sadovodstvo, vinogradarstvo $i$ vinodelie Moldavii [Gardening, viticulture and winemaking in Moldova]. -1973 . № 12. pp. 17-18.

4. Зармаев, А.А. Полуукрывная культура винограда в условиях Ичкерии / А.А. Зармаев //Виноград и вино России. - 1999. - № 3 - С. $14-16$.

Zarmaev A.A. Poluukryvnaya kultura vinograda $v$ usloviyax Ichkerii // Vinograd i vino Rossii. [Grapes and wine of Russia] 1999. № 3 pp. 14-16. (in Russian)

5. Нудьга, Т.А. Технические сорта в зоне укрывной и полуукрывной культуры винограда на Кубани / Т. А. Нудьга, Т.П. Зинченко // Виноград и вино России. - 2001. - № 4. - С. 34-36.

Nudga T.A., Zinchenko T.P. Tehnicheskie sorta v zone ukryvnoj $i$ poluukryvnoj kultury vino-grada na Kubani. Vinograd $i$ vino Rossii [Grapes and wine of Russia]. - 2001. № 4. pp. 34-36. (in Russian)

6. Малтабар, Л. М. Новые системы формирования и ведения насаждений в зоне полуукрывной культуры винограда / Л.М. Малтабар, Н.В. Матузок // Виноделие и виноградарство. - 2010. - № 3. - С. 30-33.

Maltabar L.M. Novye sistemy formirovaniya $i$ vedeniva nasazhdenij $v$ zone polu-ukryonoj kultury vinograda. // Vinodelie i vinogradarstvo [Winemaking and viticulture]. 2010. № 3. pp. 30-33. (in Russian)

7. Абдулкеримов, Г.А. Формировки винограда для полуукрывной культуры в северной зоне Дагестана // Виноделие и виноградарСтво СССР. - 1984. - № 8. - C. 28-31.

Abdulkerimov G.A. Formirovki vinograda dlya poluukryvnoj kultury $v$ severnoj zone Dagestana // Vinodelie i vinogradarstvo SSSR [Winemaking and viticulture of the USSR]. - 1984. № 8. pp. 28-31. (in Russian)

8. Караев, М. К. Новые системы ведения и формирования для северной зоны промышленного виноградарства Дагестана / М. К.
Караев // Вестник Чеченского государственного университета. 2013. - № 1(13). - C. 180-184.

Karaev M.K. Novye sistemy vedeniya i formirovaniya dlya severnoj zony promysh-lennogo vinogradarstva Dagestana [New systems of management and formation for the Northern zone of industrial viticulture of Dagestan] Vestnik Chechenskogo gosudarstvennogo universiteta [Bulletin of the Chechen State University]. 2013. № 1(13). pp. 180184. (in Russian)

9. Гусейнов, Ш. Н. Перспективы развития агротехники винограда в РФ / Ш. Н. Гусейнов, П. Д. Садчиков, Б.В. Чигрик, Н.А. Сироткина // В кн.: Организационно-экономический механизм иновационного процесса и приоритетные проблемы научного обеспечения развития отрасли. Краснодар. - 2003. - С. 375-379.

Gusejnov Sh.N., Sadchikov P.D., Chigrik B.V., Sirotkina N.A Perspektivy razvitiva agrotexniki vinograda $v R F \quad V k n$.: Organizacionnoekonomicheskij mexanizm inovacionnogo processa $i$ prioritetnye problemy nauchnogo obespecheniva razvitiva otrasli [In the book: Organizational and economic mechanism of the innovation process and priority problems of scientific support of the industry]. Krasnodar. 2003. - pp. 375-379. (in Russian)

10. Wang Shan. Защита винограда от морозов прикопкой; оценка системы формирования кордон. / Wang Shan, Li Hua, Je Qiuhong, Wang Hua // Vitis. -2016. - №2. - C 45-51.

Tang Shan. // Vitis. 2016. №2. pp. 45-51.

11. Егоров, Е.А. Виноградарство России - настоящее и будущее/ Е. Егоров, А. Аджиев, К. Серпуховитина, Л. Трошин, А. Жуков, Ш. Гусейнов, А. Алиева // Махачкала, 2004.- С. 375-379.

Egorov E., Adzhiev A., Serpuxovitina K., Troshin L., Zhukov A., Gusejnov Sh., Alieva A.Vinogradarstvo Rossii - nastoyashbee $i$ budushbee [Viticulture of Russia - present and future] Maxachkala, 2004. pp. 375-379. (in Russian)

12. Патент № 1648285. Patent № 938833. Способ ведения виноградных кустов / Гусейнов Ш.Н. Опубликовано 15.05.1991, Бюл. № 18.

Patent № 1648285. Sposob vedeniya vinogradnyx kustov./ Gusejnov Sh.N. Published 15.05.1991, Byul. № 18 [Patent No. 1648285. Patent No. 938833. Method of conducting grape bushes./ Huseynov Sh. N. Published 15.05.1991, Bull. No. 18]. (in Russian)

13. Патент № 938833. Способ формирования виноградных кустов для полуукрывной зоны / Гусейнов ШІ. Н. Опубликовано 30.06.1982, БюЛ. № 24.

Patent № 938833. Sposob formirovaniya vinogradnyb kustov dlya poluukryonoj zony. / Gusejnov Sh.N. Published 30.06.1982, Byul. № 24 [Patent No. 938833. Method of formation of grape bushes for semicontinuous zone./ Huseynov Sh. N. Published 30.06.1982, Bul. No. 24]. (in Russian) 